John Carroll University

Carroll Collected

2019

Creating Interdisciplinary Faculty Connections Through

Community as a Precursor to Enhancing Innovation, Creativity and Entrepreneurship on University Campuses

Kimble Byrd

Jacqueline Schmidt

Follow this and additional works at: https://collected.jcu.edu/fac_bib_2019

Part of the Communication Commons 


\title{
Creating Interdisciplinary Faculty Connections Through Community as a Precursor to Enhancing Innovation, Creativity and Entrepreneurship on University Campuses
}

\author{
Kimble Byrd \\ Rowan University \\ Jacqueline J. Schmidt \\ John Carroll University
}

The growth of cross-disciplinary diffusion of innovation, creativity and the entrepreneurial mindset has been significant. While many institutions have focused on curriculum and courses, this study examines the use of faculty communities through communities of practice and faculty learning communities to build a campus culture independent of size of the institution, or stage of program development. The analysis examines two distinctly dissimilar academic settings. One Rowan University, a large (16,000 student) public university with a developed program and a second, John Carroll University, a smaller $(3,100)$ private religiously affiliated university with a newly developing program. Authors share suggestions for implementation.

Keywords: cross-campus, learning communities, communities of practice and entrepreneurship

\section{INTRODUCTION}

Across every business and non-profit function, creativity is central to solving complex problems, developing new strategies, facilitating innovation, and driving change (Harvard Business Review, 2016). Courses/programs in creativity and entrepreneurship on college campuses have grown and continue to grow significantly. Prior to 2000 these programs were primarily in business schools for business students (Kurakto, 2005). However, a study by Bhide (2000) revealed only $25 \%$ of future entrepreneurs came from schools of business. As a result, universities began to examine ways to expand entrepreneurship across campus to fully engage and develop future entrepreneurs. The Kaufmann foundation was a key leader in this effort funding eight colleges (25 million dollars) in 2003 and six more (19.5 million) in 2006 (Ewing Marion Kauffman foundation, 2010) to develop entrepreneurship across campus.

Traditionally, these programs have followed the pattern of business faculty designing a course that involves students of a certain major or all nonbusiness majors. While the program is interdisciplinary as the students come from nonbusiness majors, the faculty is generally all from business. The involvement as well as the perspective of faculty from the arts and sciences is minimal. While this approach may be effective for students, it can create two problems in fully developing entrepreneurial thinking across the campus. First, as these courses are developed by business faculty, arts and science faculty do not have a 
buy in or understanding of the creative process of entrepreneurship. Therefore, they do not reinforce or incorporate the principles in the rest of the courses in their majors/programs. As a result, these courses are often viewed as an add-on for the student, not involving the faculty member. Second, arts and science faculty often perceive the purpose of these courses to develop start-ups (vocational/practical) rather than to instill an entrepreneurial mindset. This reinforces the viewpoint for the arts and science faculty that entrepreneurship is the preview of the business school and does not recognize the creativity/innovation essential to the entrepreneurial mindset. What is missing in these programs is the recognition that entrepreneurial and creative thinking is not an add-on or a method to create a business, but that shares similar values with the liberal arts and science; such as commitment to self-expression, debate, creativity, problem solving and ongoing articulation of the mutuality of social responsibility and personal identity (Godwyn, 2009). In fact, Mason and Rennie (2008) contend that entrepreneurship can be the foundation of the liberal arts education.

This paper examines a different way of spreading entrepreneurship and creativity across campus though the development of faculty learning communities or communities of practice. In this approach faculty from various departments (business, arts, humanities, and the sciences) work together to study creativity and the entrepreneurial process and then implement these principles within their own discipline's courses. Liberal arts and science faculty see how entrepreneurial thinking relates to their discipline and business faculty see a broader context for entrepreneurship and the links between fields/disciplines needed for developing ideas (Lavelle, 2013). This approach embeds the process of creativity and entrepreneurial thinking across the university curriculum, provides ownership by faculty of various disciplines outside the business school, and helps faculty from various disciplines learn from each other, share perspectives to develop new and more effective ways to infuse this knowledge into their courses.

This paper explores and identifies factors, independent of institution size and program development, that contribute to the successful implementation of a strategic plan to enhance innovation, creativity, and entrepreneurship learning through the construction of community using communities of practice (CoPs) and faculty learning communities (FLCs). This case study examines two very different institutions and approaches to foster a culture of innovation and creativity across campus. One, Rowan University, a large (16,000 student) public university and a second, John Carroll University, a smaller (3100) private religiously affiliated university These schools have different programs and resources. This case study focuses on and identifies the key characteristics, processes, methods and outcomes of programs. The authors share approaches used in developing university administration support, attracting and maintaining faculty involvement, identifying and creating faculty projects, and results.

\section{TYPES OF COMMUNITIES}

\section{Communities of Practice}

While the literature provides divergent definitions related to CoPs, this study uses that of Wenger, McDermott, and Synder (2002), where CoPs are defined as "groups of people who share a concern, a set of problems or a passion about a topic, and who deepen their knowledge and expertise in this area by interacting on an ongoing basis" (p. 4). CoPs can be viewed as informal networks that support learners in co-creating knowledge (Hara, 2008; Veenswijk and Chisalita, 2007; Porter, Donthu, MacElroy and Wydra, 2011).

Lave and Wenger (1991), the earliest proponents of the community of practice (CoP) concept, strongly viewed CoPs as a "social learning system". CoPs provide organizations with a platform for knowledge sharing and peer-to-peer learning among practitioners (Wenger, 1998; Wenger et al., 2002). In the corporate world CoPs enable companies to develop the essential portfolio of competencies to attain competitive advantage (Hafeez, Zang, and Malak 2002). In education CoPs have been developed for the purpose of generating new knowledge, faculty development, peer learning and professional development (Brooks, 2010; Zhang and Watts, 2008). 
Among the common characteristics of CoP activities include social interaction, knowledge-creation, knowledge-sharing, and identity-building (Li, Grimshaw, Nelson, Judd, Coyte, and Graham, 2009). CoPs require bringing together the right people and providing a supportive infrastructure to facilitate exchanges. Developing closer working relationships and sharing common values is an important step in this process (Thomson and Wright, 2013). According to Wenger et. al. 2002 the values identified as critical for CoPs are:

- social and intellectual leadership for the community of practice;

- a shared passion for the topic that energizes the community;

- the self-selection of members to join the community; and

- the ability of the community to define its own domain to ensure that potential members feel personally connected to the group's area of interest.

\section{Faculty Learning Communities}

A FLC is defined as a structured group of faculty and staff (6-12 members) engaging in an active, collaborative, yearlong program to enhance teaching and learning with frequent seminars and activities that provide learning and community development (Cox and McDonald, 2017). There are generally two types of learning communities: cohort based (often for junior faculty) or topic based (open to all faculty). Faculty learning communities are voluntary, usually cross- disciplinary, driven by faculty interest in the topic, and while focusing on getting things done, often have more focus on the social aspects of building community. Wenger (1998) identified a faculty learning community as a special kind of community of practice. While FLCs and CoPs share many characteristics (passion for subject, social interaction), Cox and McDonald (2017) comparing the features of the FLC at Miami University (now the U. S. model for FLCs) and a $\mathrm{CoP}$ at University of Southern Queensland in Australia identified several differences. Among the differences were: time frame (FLC usually a year, $\mathrm{CoP}$ has no time limit); member participation (FLC by application, CoP by invitation); and leadership (FLCs leader is a full participant in program, CoP distributed leadership).

\section{CASES}

For potential adopters the "threshold" question is both literal and figurative, that is where do you start? Additionally, how do you create a broad-based community of likeminded individuals but disparate disciplines to decide learning goals, opportunities and techniques? The following cases will identify two different methods and approaches depending on the context of the institution.

\section{Rowan University}

The second largest $(16,000)$ University behind Rutgers in the state of New Jersey, Rowan is organized into eight colleges by subject matter area. The College of Business with six majors and 2000 students is among the largest. Within the College of Business, entrepreneurship is paired with management in its own separate department. The Entrepreneurship Program is relatively mature, with a major, minor, and a center for entrepreneurship. Across the campus, students from such diverse fields as engineering and music business have a required course, Entrepreneurship and Innovation, the gateway entrepreneurship course for all students.

The benefits of the merge of critical thinking plus ideation, creativity has been recognized as a desired proficiency in any discipline and it was that realization which drove the creation of a cross-campus initiative to include creativity and innovation in the experiences of more students, both within and outside their specialized fields. An interdisciplinary group of faculty received the opportunity to explore the scale, scope and means of disseminating the knowledge of entrepreneurship, skills of innovation and ability to create.

The means used to move this effort forward was to embark on a charrette. The teaching goals, means and solutions were derived from a university-wide charrette, an assemblage of all stakeholders in an effort 
to map solutions after resolving conflicts. It included representatives from most of the university's colleges: Arts and Humanities; Education; Math and Science; Fine and Performing Arts and Communication; in addition to Engineering and Business and members from business community advisory groups. This day long moderated session was supported by the Dean of the College of Business.

The challenge for educators is of course to design learning environments and instruction so that students will be able to use what they learn in appropriate new contexts - that is, to enable the transfer of learning. The two questions primarily deliberated: what outcomes were desirable in terms of durable knowledge and skills and what learning strategies were appropriate and how might these be cultivated. These strategic goals increased the need for faculty proficiency within individual disciplines in imparting these learnings. Enhanced faculty professional development, through the sharing of knowledge "across the campus" through a community of practice model was the strategy crafted to accomplish these aims.

The Rowan University Entrepreneurship Across the Campus Initiative (CoP) emerged through the charrette and from dual-track strategic planning in the Colleges of Business and Engineering and evolved over two semesters as a proactive means of addressing the desire to have students be exposed and build upon an entrepreneurial skillset and more importantly, facilitating an entrepreneurial mindset.

To provide added standing and credibility to the effort, conversations were then held with the Faculty Center Excellence in Teaching and Learning Center. The center provided valuable and appropriate connections across campus as it serves faculty, pertinent supporting offices, and the institution in pursuit of teaching, scholarship and creative excellence. Its imprimatur was sought and received. This linkage provided twofold benefits: follow-on support and the ability for faculty involved to utilize program participation in their tenure and re-contracting portfolio. Participation therefore "counts" as the accomplishment of the program becomes part of the vita.

A Teaching Certificate approach was determined to be the best mechanism to address the goals and purpose of the budding Community of Practice, as it equips multidisciplinary faculty to utilize assignments that promote creativity, innovation and entrepreneurship. This "enable the enabler" model allows experienced course designer or subject-matter expert facilitators to demonstrate to lessexperienced faculty member how to convey innovation and creativity skills and mindsets through exercises, gaming, simulations, and modules. Greenfield, Travaglia, Nugus, and Braithwaite (2007) elucidate the theoretical foundation for this approach. They systematically review the determinants of the diffusion of innovations in health service delivery and organization. Of the factors influencing the spread of innovation four are salient and necessary to create the community of practice.

\begin{tabular}{|l|l|l|}
\hline ELEMENTS & EXPLANATION & IMPLEMENTATION/OR \\
\hline Social network structure & $\begin{array}{l}\text { (Horizontal networks for } \\
\text { spreading peer influence, vertical } \\
\text { networks for cascading } \\
\text { authoritative information) }\end{array}$ & Cross-Disciplinary cohorts \\
\hline $\begin{array}{l}\text { Support of the innovation by key } \\
\text { individuals or champions in a } \\
\text { social network }\end{array}$ & $\begin{array}{l}\text { (Influencers and gatekeepers) } \\
\text { Organizations which support } \\
\text { boundary-spanning roles }\end{array}$ & $\begin{array}{l}\text { (Resource provisions and } \\
\text { providers) } \\
\text { (Engineering, Math/Science and } \\
\text { Business) }\end{array}$ \\
\hline $\begin{array}{l}\text { A planned and formal } \\
\text { dissemination program that is } \\
\text { tailored to the needs and } \\
\text { perspectives of potential adopters }\end{array}$ & $\begin{array}{l}\text { Provost level resource support } \\
\text { for Entrepreneurship Across the } \\
\text { Campus (EAC) }\end{array}$ \\
\hline
\end{tabular}


The most important first step in crafting any pedagogical system is creating learning outcomes. They are integral to and a precursor for good course design and development. With considered reflection, the Certificate Program identified five.

After participation in the Innovation \& Entrepreneurship Faculty Training Certificate, faculty will be able to:

$\checkmark$ Identify innovation \& entrepreneurship activities that can be integrated within their designated classes

$\checkmark$ Describe the benefits associated with innovation \& entrepreneurial based activities and how they contribute positively to students' mindset

$\checkmark$ Create an instructional plan for the implementation of a specific type of innovation and entrepreneurship teaching method including student learning outcomes and potential assessment strategies

$\checkmark$ Document the outcomes of the implementation of the innovation \& entrepreneurship teaching strategy.

$\checkmark$ Analyze the implementation and determine what worked, what did not work, and additional resources needed if continued implementation is desired

To accomplish these ends, four certificate topical areas were the modalities for engaging the program cohort after a full day immersion boot camp: Creativity Generation Exercises; Idea Generation Methods; Innovation Canvas; and a multivariate Business Model Canvas.

The overarching goal for the CoP was to facilitate faculty inculcating innovation and entrepreneurship into their classes. The concepts covered ranged from basic techniques to increase student's creativity and idea generation process to more sophisticated techniques such as how to use the business model canvas. Faculty were exposed to these techniques through a series of 75 minute workshops that were kicked off with a one day boot camp designed to allow faculty to identify a course they are teaching that would benefit from the integration of these principles, identifying the learning objectives they hope to achieve through the addition of the innovation and entrepreneurship activity and creating a proposed implementation plan for the upcoming academic year.

The boot camp was an effort to prepare faculty to be ready to implement the techniques from the certificate program into their classes. It served as the foundation for their proposed academic year plans. It provided faculty members with an overview of the importance of entrepreneurial mindset (knowledge, skills and attitudes) and how this mindset benefits all types of disciplines. In addition, it delivered a highlevel description of the four topic areas that build the scaffolding that was delved into in further detail during the certificate series.

By the end of the boot camp faculty could:

$\checkmark$ Analyze the implementation and determine what worked, what did not work, and additional resources needed if continued implementation is desired

$\checkmark$ Identify a course they teach in which they would like to integrate innovation and entrepreneurship activities

$\checkmark$ Determine what aspect of the course they would like to integrate the activities and developed an instructional plan for their implementation. Examples include lecture activities, case study, homework, projects, etc.

$\checkmark$ Create student learning outcomes they believe will be influenced by the integration of these techniques and incorporated these within the syllabus for their course

$\checkmark$ Prepare an outline of potential assessments they could use as tools for measuring whether the students are achieving their proposed learning outcomes

These documents served as living artifacts that faculty members were able to update and build upon over the course of the academic year as they participated in the CoP certificate series. 


\section{Outcomes}

A preliminary analysis was performed on implementation to determine what worked, what didn't, and additional resources needed if continued implementation is desired. The Rowan program is in its third iteration, as such there exist nascent data on the participation and impact of the certificate.

\section{Faculty Composition}

Originally designed for cross-campus sharing, while still led by business faculty the composition indicates that inclusion existed as most of the colleges within the university were in the CoP: $35 \%$ Business; 20\% Engineering; 15\% Math/Science; 10\% Humanities; 10\% Communications; and 10\% Education.

\section{Enrollment Numbers}

Initially designed for mid-sized cohorts, the overwhelming demand of the first assemblage was rightsized in the latter two years. Registrants totaled 40 in 2016-17; 22 in 2017-18; and 21 in 2018-19.

\section{Assessment}

Sixty-seven percent of the faculty completed the program and received the certificate. End of sessions surveys were conducted. Among the responses two are especially significant: $75 \%$ Rated topical sessions "Very Good-Excellent" and 86\% "Would Recommend to Colleagues". In short, the Rowan approach of sharing examples of evidence-based practice and innovative approaches within a Community of Practice is a strategic pathway towards diffusing a culture of innovation across the campus that is more likely to lead to changes in practice than simply disseminating new knowledge.

\section{John Carroll University}

John Carroll University is a private, religiously affiliated (Jesuit) school with 3100 undergraduate students and 400 graduate students. At the time of this program, the school had a college of arts and sciences with eighteen majors and a school of business (now College) with six majors. Entrepreneurship was an interdisciplinary minor for students from both the arts and sciences and business housed in a Center for Entrepreneurship and reporting to both CAS and Business School Deans. The program was relatively new graduating it first minor in 2012. Faculty from both the arts and sciences and business taught in the program.

The support and idea for the John Carroll Creativity and Entrepreneurship FLC emerged from faculty teaching in the interdisciplinary Entrepreneurship Minor and recent university core revisions identifying creative and critical thinking as one of the university's core values. The goals of this initial faculty group were to develop a stronger interdisciplinary base of support for and understanding of the entrepreneurial mindset and its relationship to the core values of creative and critical thinking; and to develop faculty practitioners/leaders in several majors on campus.

The strategy developed by this group was to create a faculty learning community. The FLC had two purposes: to increase the faculty member's knowledge about creativity and innovation and to spread courses on creativity and entrepreneurship throughout the university's curriculum. To complete the second goal each faculty member in the FLC was to create, share and use an activity/exercise that incorporated the principles of creativity and entrepreneurship in relationship to one of the courses they taught in their own majors.

Supported by university administration (both the college of arts and sciences, the school of business and the university's center for teaching and learning) and a grant from the Burton D. Morgan Foundation, a general call was sent to interested faculty to apply for the program. A general call rather than targeting specific departments was the strategy because the focus was to attract and develop faculty who were interested, as they could become examples and leaders to other faculty in their disciplines. Twenty faculty were accepted and provided with a stipend for their involvement. Participating faculty in the learning community were from sociology, religion, communication, history, psychology, education, physics, 
economics, management, accounting, political science, counseling, exercise science, and theatre. The FLC commitment was for two semesters.

The approach used in developing the FLC in the first semester was a series of meetings to discuss shared readings and participate in workshops led by national leaders in creativity. All faculty read Group Genius by Keith Sawyer and Cracking Creativity: The Secrets of Creative Genuis by Michalko. These two books were chosen because they were books read in the entrepreneurship minor's first course and provided a context/connection for the FLC with existing faculty working in entrepreneurship and creativity at the university. There were two workshops for the FLC. The first was on creating the climate for innovation and creativity and understanding individual problem-solving style differences. All faculty completed a VIEW analysis of their leadership style before the session. The second workshop focused on breaking assumptions in development ideas and generating new approaches. Following these meetings, faculty worked together during the second semester in creating exercises that they could use in their discipline. The FLC met a series of five times during the second semester, the first three on sharing, brainstorming and developing the exercises. In the last two meetings, each member of the FLC shared their exercises with the group and received feedback. The FLC built cross discipline connections for the community and showed members how the entrepreneurial mindset could be used in different disciplines. The result was that faculty not only understood how they could use these principles, but also could explain to other faculty how they might apply to their discipline.

The learning community presented their exercises to the university community during the University's celebration of scholarship week. Additionally, the exercises were available on separate site on the university canvas system, identifying the faculty member of the learning community and class in which the exercise occurred. This canvas site was open to all faculty at the university and faculty were encouraged to ask individual faculty from the learning community about their exercises or for advice in creating new exercises. The strategy in posting names was that a faculty member in sociology might be more comfortable asking another sociologist about how to incorporate these principles into their classes than asking someone from management. One additional effect has been that the postings have allowed faculty from various disciplines to see the use of these principles in other disciplines created some interesting cross-discipline connections. Faculty from the learning community were encouraged to update the canvas site and other faculty to join and post their exercises.

\section{Outcomes}

The FLC at JCU accomplished its goals. Through the construction of an FLC using a social network of shared knowledge and peer influence/leadership, the recognition that the entrepreneurial mindset is a part of all disciplines and the practice of the principles of entrepreneurial mindset increased on the campus. Additionally, the FLC created a group of twenty faculty members who understood creativity and entrepreneurship and were able to apply these approaches into their own courses, but also could explain to other faculty how they might apply to their discipline. As a result, these faculty did become champions for promoting creativity and entrepreneurship across campus.

Two issues emerged from this approach. First, the size of the FLC was problematic. As previous literature suggests, the ideal size for FLC's should be 8-10 to allow for development. The size of the program (20 faculty) made it harder for total faculty engagement and the group was often broken down into smaller subgroups for work in the second semester. A suggestion would be to use a smaller group as it would be more manageable for both the program and the university budget. Second, because the FLC lasted for one year as do most learning communities, there was no continuation or follow up other than the canvas site. For ongoing success, the program needed more connection to the JCU Center for Teaching and Learning and to be offered to new faculty each year to continue to develop more faculty involvement and spread creativity, innovation and entrepreneurship across the campus. Offering this opportunity yearly would also allow members from earlier learning communities the opportunity to work with and interact with new members as they develop their exercises building a stronger outreach.

Overall, the FLC was a good way to begin this process at JCU and should be encouraged for schools just starting this process or with beginning programs to gauge the interest at their institution among both 
faculty and administration. The FLC allowed faculty to explore an area of interest, as FLC's do, without a substantial commitment from the University. Furthermore, because faculty were engaged for a year rather than attending a one-time program/speaker without follow up, a community of interdisciplinary faculty members who strongly support this area emerged. However, as programs develop this process should be made more a part of the overall university experience and deviate from the FLC model slightly moving more to a community of practice. The JCU program should be offered yearly and provide for connections with earlier learning communities to develop more of an ongoing community of teachers and scholars across the campus. Currently, the Muldoon Center for Entrepreneurship at JCU is working on developing such a program.

\section{CONCLUSION}

The authors have provided a descriptive analysis of diverse institutions with the idea that it might prove useful to those who are contemplating initiating or enhancing the inculcation of creativity and innovation in college and university students across disciplinary boundaries. Utilizing new requirements/courses/books are alternatives, but we believe the optimal route is through generating interest and ability in the faculty, who then create an organic pedagogical cascade. Utilizing active exemplars of the concepts of Communities of Practice(CoPs) or Faculty Learning Communities(FLCs), this work has explored and characterized individual and institutional factors such as the size of school, support of institution and faculty, developmental stage of the program, and resources that contribute to the fruitful execution of academic strategic planning approaches to infuse innovation, creativity and entrepreneurship across campus using community. These approaches will integrate and augment the curriculum, accelerate learning impact time, and reduce subject matter compartmentalization of the curriculum. Prescriptively we have shown the underlying theory, implementation strategies and preliminary outcomes which contribute to the transferability of these approaches to any learning institution.

\section{REFERENCES}

Bhide, A. (2000). The Origin and Evolution of New Businesses. New York: Oxford University Press.

Brooks, C. (2010, August). Toward 'hybridised' faculty development for the twenty-first century: blending online communities of practice and face-to-face meetings in instructional and professional support programmes. Innovations in Education and Teaching International, 47(3), 261-270.

Cox, M., \& McDonald, J. (2017). Faculty Learning Communities and Communities of Practice Dreamers, Schemers, and Seamers. in Eds. McDonald, J, Colter-Steel, A., Communities of Practice, 47-72, Springer, Singapore.

Ewing Marion Kauffman Foundation. (2010). Entrepreneurship Education without Boundaries: Kauffman campuses seek to make entrepreneurship a college-wide experience. Retrieved from http://www.kaufmanorg;entrepreneurship/kauffman-campuses

Greenfield, D., Travaglia, J., Nugus, P., \& Braithwaite J. (2007). Health Sector Community of Practice Literature: Final Report. A Content Analysis and Systematic Review of the Health Community of Practice Research Literature. Sydney, Australia, Center for Clinical Governance Research in Health, Faculty of Medicine, University of New South Wales.

Godwyn, M. (2009, June). Can the Liberal arts and Entrepreneurship Work Together? Academe, American Association of University Professors.

Hafeez, K., Zhang, Y., \& Malak, N. (2002). Core competence for sustainable competitive advantage: A structured methodology for identifying core competence. IEEE Transactions on Engineering Management, 49(1), 28 - 35. DOI:10.1109/17.985745, Source IEEE Xplore. 
Hara, N. (2008, December). Communities of Practice: Fostering Peer-to-Peer Learning and Informal Knowledge Sharing in the Work Place. DOI: 10.1007/978-3-540-85424-1, ISBN: 978-3-54085423-4.

Harvard Business School Executive Education. (2016). Retrieved March 2017.

Kurakto, D. (2005). The emergence of entrepreneurship education: Development, trends, and challenges. Entrepreneurship Theory and Practice, 29(5), 577-598.

Lave, J., \& Wenger, E. (1991). Situated Learning: Legitimate Peripheral Participation. Cambridge: Cambridge University Press. http://dx.doi.org/10.1017/CBO9780511815355.

Lavelle, L. (2013, April 10). Business schools embrace the Liberal Arts. Bloomberg Businessweek.

Li, L., Grimshaw, J., Nelson, C., Judd, M., Coyte, P., \& Graham, I. (2009). Evolution of Wenger's concept of community of practice. Implementation Science, 4(1), 11.

Mason, R., \& Rennie, F. (2008). E Learning and social networking handbook. New York: Routledge.

Porter, C. E., Donthu, N., MacElroy, W. H., \& Wydra, D. (2011). How to Foster and Sustain Engagement in Virtual Communities. California Management Review, 53(4), 80-110. https://doi.org/10.1525/cmr.2011.53.4.80

Thomson, L. Schneider, J., \& Wright, N. (2013). Developing communities of practice to support the implementation of research into clinical practice. Leadership in Health Services, 26(1), 20 - 33.

Veenswijk, M., \& Chisalita, C. (2007). The importance of power and ideology in communities of practice. Information Technology and People, 20(1), 32-52. https://doi.org/10.1108/09593840710730545

Wenger, E. (1998). Communities of Practice: Learning, Meaning, and Identity. Cambridge: Cambridge University Press.

Wenger, E., McDermott, R., \& Snyder, W. (2002). Cultivating Communities of Practice. Boston, Harvard Business School Press.

Zhang, W., \& Watts S. (2008). Online communities as communities of practice: a case study, 12(4), 5571. DOI 10.1108/13673270810884255. Q Emerald Group Publishing Limited. 